This paper is published as:

Druckman, A., P. Sinclair and T. Jackson (2008). "A geographically and socio-economically disaggregated local household consumption model for the UK." Journal of Cleaner Production 16(7): 870-880

\title{
A geographically and socio-economically disaggregated local household consumption model for the UK
}

\section{Druckman, $A_{.}^{1,2 *}$, Sinclair, $P_{.}{ }^{2}$ and Jackson, $T_{.}^{1,2}$ Centre for Environmental Strategy, University of Surrey, UK}

Author affiliations:

${ }^{1}$ Research Group on Lifestyles, Values and Environment (RESOLVE), University of Surrey, UK.

${ }^{2}$ Centre for Environmental Strategy, University of Surrey, UK.

\section{Abstract}

A key challenge for local environmental and economic planning is to predict resource flows and material waste arisings at a high level of geographical localisation. This paper presents an approach to household consumption modelling in which the material demands of small socio-economically homogeneous neighbourhoods are estimated on the basis of consumer expenditure data in conjunction with Census data. Household waste arisings are estimated through incorporation of a household metabolism model. Selected material flows of consumer commodities, such as household appliances, carpets and clothing, are examined in case study areas representing extremes of relative deprivation, and neighbourhoods representing typical examples of the UK National Classification of Census Output Areas. The model will be of use in sustainable consumption policy-making and local waste strategy planning.

\footnotetext{
* Corresponding author: Angela Druckman Centre for Environmental Strategy University of Surrey Guildford GU2 7XH, UK Email: a.druckman@surrey.ac.uk Tel: $+44(0) 1483686679$ Fax: +44(0)1483686671
} 
Keywords: sustainable consumption; household consumption; local waste strategy; material flow analysis (MFA).

\section{Introduction}

Materially intensive consumption patterns and lifestyles present a major challenge to sustainability: resources are finite; there is limited capacity provided by the environment for disposal of wastes; and the use of materials is contributing to global environmental problems such as climate change [1-4]). In particular, the increasing quantity of waste produced by households has significant environmental impacts. For example, landfill sites produce toxic leachate and greenhouse gases, and there is a scarcity of sites available for landfill. Traditionally waste has been treated as an 'end of pipe' problem, but there is now a move amongst policy-makers to address the problem of waste by taking a whole life cycle approach to resource and waste management. Accordingly, the emphasis is now focused more towards reducing the demand for new resources, involving, for example, ecodesign of goods, with increasing rates of repair, re-use, re-manufacture and recycling, thus aiming to achieve waste reduction. The starting point for such an approach must be an understanding of the upstream flow of resources through the economy and through households [5, 6].

The Local Area Resource Analysis model (LARA) described in this paper presents a framework that maps resource use, from a consumption perspective, through UK households grouped by highly socio-economically and geographically disaggregated areas, and relates resource use to waste arisings. Results generated by LARA add to the evidence base in several ways. First, it can be used to identify the demand for specific commodity types (and waste arisings) in a given geographical area. Next, it can be used to identify when and where opportunities for repair, re-use, re-manufacture and recycling arise and match these opportunities to available reuse or recycling facilities. Furthermore, LARA can start to answer questions about the resource consumption of specific socio-economic and lifestyle groups. Finally, LARA can, in principal, relate household resource use to local institutional infrastructure, and this will give us an insight into the extent to which households are "locked" into unsustainable consumption patterns through the infrastructure in which they operate [7-9].

LARA originated from an objective to estimate the waste arisings from households. The environmental impacts of those arisings depend on a number of factors, including the toxicity and fate of the wastes. A full lifecycle assessment (LCA) of waste arising (or indeed of resource use) is beyond the scope of this paper, although it has 
been the focus of a number of other studies [10-12]. Rather, LARA is a pragmatic framework that adopts a streamlined approach to environmental assessment based on principles of materials flow analysis [4, 13, 14]. Its strength lies in its ability to estimate very specific material demand and waste arisings in highly geographically and socio-demographically disaggregated areas.

In pursuit of these aims, the paper is organised as follows: the methodological approach adopted is described in Section 2, and the assumptions and limitations outlined in Section 2.4. In Sections 3.1 and 3.2, material demands for selected consumer commodities (household appliances, carpets, and women's' and girls' outer garments) for selected case study areas are presented, and estimation of waste arisings is contained in Section 3.3. A discussion concerning validation of the model is provided in Section 3.4. The paper concludes by synthesizing the contribution the model makes to the evidence base for policy-making, and includes recommendations concerning data provision. A glossary of terms is placed after the conclusion.

\section{Methodological approach}

This paper describes a model called Local Area Resource Analysis model (LARA), and presents an example of one of its uses. LARA quantifies average household expenditure of small socio-economically homogeneous local areas in England and Wales, and by applying the mass balance principle, which states that resource flows into a system must equal the resource flows that come out of the system plus stock accumulated [15], material demand is calculated. As an example, this paper shows how the material demand calculated from LARA can be used to estimate household waste arisings. This calculation is based on a household metabolism model, in which stocks held in households are assumed to be related, amongst other factors, to household socio-economic characteristics. Other uses of LARA include, for example, investigation of material consumption inequalities at local area level [16]. Accredited, national, regularly-updated data-sources are used and therefore, the methodologies described are replicable for other commodities and areas, and can be updated for future years.

The current version of LARA models direct resource flows only; these are the flows that are physically demanded by the households of neighbourhoods under study. Indirect resource flows, that are upstream flows associated with the production of consumer goods $[17,18]$, are excluded in this version. Thus for example, the current model takes account of, in principle, materials and packaging concerned with the demand for a carpet, 
but excludes resources used by the supply chain to produce it. Full resource versions of LARA are currently being developed, based on input-output analysis [19-21]. One version will include estimation of upstream (indirect) resource flows, while another will estimate upstream (indirect) waste arisings. A further version of LARA that is under development will assesses climate change impact due to direct and indirect energy use using carbon dioxide emissions as a proxy indicator.

In the following subsection, we present the methodology employed within LARA. A more detailed description can be found in Druckman et al. [22].

\subsection{Local Area Resource Analysis model (LARA)}

LARA analyses the material demand of households in local areas. This study covers years 1996/7 to 2003/4. For the purposes of the study, local areas are based on Output Areas (OAs) as defined in the UK 2001 Census [23]. Use of OAs gives the highest level of geographical detail available from Census 2001. OAs are small areas of approximately 124 households on average, that are as socially homogeneous as possible, based on tenure of household and dwelling type. LARA uses Census 2001 definition of a household unit, which defines a household as "one person living alone, or, a group of people living at the same address with common housekeeping - that is, sharing either a living room or at least one meal a day" [24]

In order to estimate average household expenditure in each local area an indirect approach is adopted. Socioeconomic and demographic characteristics of households in each local area are found from the Census. The average expenditure of households with matching socio-economic characteristics is then calculated from the Expenditure Survey, and thus average household expenditure of each local area is determined. This approach is illustrated in Figure 1 and can be explained in more detail as follows. Households in each OA are classified into Household Categories (HoCs). Table 1 shows how each of the 45 HoCs (labelled A-AS) is uniquely described by the characteristics of age and economic status of the Head of Household (HRP) and by type of dwelling and tenure. The proportion $p_{i}$ of households in a local area that belong to each HoC $i$ is found from the Census. For example, in one highly affluent local area the percentage of households in HoC category F (defined as HRP aged $30-49$, employed, in a detached house which he/she owns) is $59 \%$ so $p_{F}=0.59$. In a highly deprived area where there are no households in this category $p_{F}=0.00$. The set of $p$ values for each local area is held in the Local Area Characteristics Database, as shown in Figure 1. 
Expenditure data are obtained from the Expenditure Survey ${ }^{1}$. The Expenditure Survey captures detailed family spending for a sample of approximately 7,000 households per annum and includes details of household characteristics [25]. By classifying each case study household in the Expenditure Survey into its appropriate HoC, average annual expenditure $\left(e_{i}\right)$ of each $\mathrm{HoC}$ is calculated. This is held in the Household Expenditure Database (Figure 1). Expenditure data are classified in functional use categories until 2000-01, and according to Classification of Individual Consumption by Purpose (COICOP) [26] thereafter.

Average household expenditure $E_{k l}$ on consumer commodity $k$ in local area $l$ is found by summing the average annual expenditure $e_{i}^{k}$ of households in HoC $i$ on commodity $k$ (from the Household Expenditure Database) weighted by the proportion $p_{i}^{l}$ of households in local area $l$ that are members of HOC $i$ (from the Neighbourhood Characteristics Database).

$$
E^{k l}=\sum_{i=1}^{i=N} p_{i}^{l} e_{i}^{k}
$$

where

$E^{k l}=$ average annual household expenditure in local area $l$, on commodity $k$

$p_{i}^{l}=$ proportion of households in local area $l$, that are members of HoC $i$

$e_{i}^{k}=$ average annual household expenditure commodity on $k$, of households in HoC $i$

$i=\mathrm{HoC}$ number, such that $i=1$ to $\mathrm{N}$, where $\mathrm{N}=$ total number of HoCs $(\mathrm{N}=45)$

In order to produce time-series results, adjustments are made to $E^{k l}$ to account for inflation by normalising expenditure to 2005 prices using the Consumer Prices Index (CPI $)^{2}$.

Physical material flows are calculated from expenditure, $E^{k l}$ by applying conversion factors obtained from two sources. For food and drink, information from Family Food (which is part of the Expenditure Surveys) is used, where annual data on average expenditure per capita and consumption in physical units (kg, litres) are given [27]; from this the average price per unit of physical commodity is calculated for each year. For other consumer commodities UK Trade Data are used ${ }^{3}$. This dataset provides import and export data in both monetary and

\footnotetext{
${ }^{1}$ The Expenditure Survey comprises the Expenditure and Food Survey (EFS), undertaken annually from 200102, which replaced the Family Expenditure Survey (FES) and the National Food Survey (NFS) which were undertaken annually in prior years [25]

${ }^{2}$ Available from the Office for National Statistics (www.statistics.gov.uk).

${ }^{3}$ Available from UKTradeInfo (www.uktradeinfo.com/).
} 
weight terms for a range of commodities, from which the average price per unit weight of goods is computed ${ }^{4}$. Ideally domestic production data would also be used. These are available from PRODCOM ${ }^{5}$. However, due to disclosure issues, there are gaps in this dataset at high levels of disaggregation. Therefore import data only are used in the current version of the model, under the assumption that imports are competitive with domestic production. As domestic production often represents the high quality end of the market, the monetary price per unit weight may be under-estimated in the model, and therefore total weight demand slightly over-estimated.

UK Trade Data are provided using EU Combined Nomenclature (CN) [29]. Cross classification is required with UK household expenditure data from the Expenditure Surveys, which, as described above, are in functional units before 2001/2 and COICOP thereafter. As these three datasets use different classifications that often do not correspond precisely, some aggregation is necessary, but highest possible levels of disaggregation are maintained. UK Trade Data are provided in producer prices which are converted to purchaser prices by adding margins and taxes less subsidies using data from the Supply Table in the National Accounts ${ }^{6}$.

\subsection{Choice of case study areas}

LARA is applicable to every small geographical OA in England and Wales. In order to facilitate analysis and discussion concerning the material flows in areas of varying socio-economic and demographic composition, specific case study areas were selected for scrutiny. Two sets of case study areas are used: the first set is of "typical" areas representative of neighbourhoods in England and Wales (an explanation of the meaning of "typical" follows); the second set looks at areas of extreme deprivation and affluence. The first set, "typical" areas representative of neighbourhoods in England and Wales, were chosen using the UK National Output Area Classification (OAC) system. The OAC system classifies OAs into 7 super-groups, 21 groups and 52 sub-groups $[30]^{7}$. The names of the 7 super-groups are shown in Table 1; in this paper one local area is chosen to illustrate the resource demands of each super-group. The second set of case study areas enables material demands in areas of extreme deprivation and affluence area to be analysed. These case study areas were chosen with reference to

\footnotetext{
${ }^{4}$ UK Trade Data provides data on gross weight of commodities, which includes the weight of packaging; this is assumed to be negligible for the commodities selected from this data source for this case study.

${ }^{5}$ PRODucts of the European COMmunity (PRODCOM) is a survey of UK manufacturers carried out by The Office for National Statistics [28].

${ }^{6}$ Available from http://www.statistics.gov.uk/. Data cover all products and do not specifically apply to imports to households. A pro-rata approach is used to estimate purchaser prices.

${ }^{7}$ OAC classifies Census 2001 OAs based on cluster analysis; it uses 41 variables that are chosen to represent the main dimensions of the Census 2001 data with the minimum number of variables [30].
} 
the Index of Multiple Deprivation (IMD) 2004 [31]; case study areas were selected that are within the lowest and highest $1 \%$ on the IMD scale.

\subsection{The household metabolism and estimation of waste arisings}

This part of the study shows how material demands calculated using LARA can be used to estimate household waste arisings ${ }^{8}$. Household waste arisings depend on gross mass of material entering households, the nature of the commodity, its packaging, and the time for which the commodity resides in the household before being discarded. It is reasonable to assume that all packaging has a short lifespan, and some commodities, typically food and drink, also have short product lifespans; for these items we assume that the time in stock is less than one year and therefore, waste arises in the year the product is purchased. To demonstrate estimation of household waste arisings due to short product lifespan commodities, glass waste from wine and champagne consumption in two case study areas is modelled.

To estimate waste arisings due to items that remain in stock for a number of years the Weibull function is used [32]; this gives a near normal distribution and enables all materials to eventually enter the waste stream [33]. The time for which a commodity resides in a household is assumed to be partly determined by manufacturer's designed product lifespan, and partly determined by the household metabolism. The household metabolism may be related to household socio-economic characteristics [34]. Use of LARA combined with the Weibull function enables household waste arisings to be estimated, in principle, specific to local area characteristics by modulating product lifespans depending on the set of $p$ values held in the Local Area Characteristics Database. The methodology is demonstrated for a sample commodity (carpets) for one case study area for three different scenarios (High Sustainability, Low Sustainability, and Constancy) for years 1996/7-2018/9. After 2003/4, High Sustainability assumes that product lifespans increase and demand decreases. Low Sustainability assumes that product lifespans decrease and demand increases. Constancy assumes constant lifespans and demand after 2003/4. The assumptions made in each of these scenarios are summarised in Table 3; assumptions concerning product lifespans combine effects due to manufacturer's design life and household metabolism effects.

\footnotetext{
${ }^{8}$ In this paper all commodities that are discarded from households are classed as waste arisings. No distinction is made between various disposal options such as re-use, recycling or remanufacturing.
} 


\subsection{Assumptions and limitations}

This study, which covers years 1996/7-2003/4, is based on population data from Census 2001. The Census is carried out at 10 year intervals, and the study period start year is the midpoint between the 1991 and 2001 Censuses. Census 2001 is considered the most complete and reliable socio-economic dataset available in the UK, providing an incomparable depth of information with comprehensive geographical coverage [30, 35]. Although some exceptional areas may change notably due to regeneration initiatives, it is assumed that the general socioeconomic hierarchy of geographic areas is relatively static throughout the study period [30].

A further limitation in the current model is that conversion from monetary to mass units of consumer products, with the exception of food and drink, are calculated for 2001 only, and the Consumer Price Index (CPI) is applied to adjust for other study years. However, in the case of some commodities, including clothing and carpets, the conversion values found from UK Trade Data were found to be anomalous for the year 2001. Linear regression was therefore, used to estimate values for 2001.

Another limitation in the model is its use of average expenditure to physical unit conversion values for all items within one commodity category. When purchasing any commodity, a consumer is generally presented with a range of prices, from expensive luxury goods to cut-price goods. The choice of purchase within this range can be considered to depend on three major factors. The first factor concerns affordability. Affordability may be modelled using price elasticities, and we may generally expect the elasticity of goods to be higher for deprived socio-economic groups than for more affluent groups. According to this assumption, material demand will be over-estimated in affluent areas and under-estimated in deprived areas. It is possible that, in future work, a module could be added to LARA, which would model the price elasticities of various consumer goods against socio-economic characteristics, and this could be used to modify the expenditure to physical unit conversion values used within LARA.

The second factor influencing the purchase choice of a consumer good within a given price range can be considered to be lifestyle. To understand this we need to look at the different roles that consumer goods play in modern society. Consumption satisfies our functional needs for food, housing, transport and so on, but consumer goods also play important symbolic roles in our lives which allow us to engage in vital 'social conversations' about status, identity, social cohesion, and the pursuit of personal and cultural meaning [36, 37]. Thus, for 
example, people to whom the status provided by the make and model of the car they purchase is of extreme importance, may choose a more expensive vehicle than someone of comparable affluence to whom such status symbols have little importance. The relationship between the choice of consumer goods within a given price range with lifestyles is complex and hard to take account of within LARA.

The third major influence on the choice of purchase of a consumer good from a given price range depends on access to, and perfect information of, the entire price range. Residents in deprived areas tend to have restricted access to affordable goods either due to physical inaccessibility (as documented in the debate concerning 'food deserts'), lack of private or public transport, and lack of internet access [38-40]. Therefore, according to this argument, material demand in deprived neighbourhoods may be over-estimated. From this discussion it can be seen that relating the purchase choice of a consumer good within a given price range to the socio-economic characteristics of households or neighbourhoods is a complex task, which is beyond the remit of the current LARA study, but which may be addressed in future work.

The ability of LARA to estimate material demand at high levels of socio-economic and commodity disaggregation are limited by the sample size of the Expenditure Survey. In particular, analysis of relatively infrequently purchased commodities such as hard floor coverings is limited, whereas analysis of more frequently purchased commodities, such as clothing, is less limited. Demand for commodities is therefore averaged over several years in the results that follow to increase reliability. An important policy conclusion from this study is that the sample size of the Expenditure Survey needs to be considerably larger if it is to be useful in this kind of analysis.

\section{Results and Discussions}

\subsection{Commodity demand in typical OAC areas}

In this section results obtained from LARA for average household material demand of selected consumer commodities (Clothes Washer/Driers, Carpets, and Women's and Girls' Outer Garments) in the set of case study areas representing OAC super-groups are presented and discussed. These results illustrate the relative mass throughput of materials in the different types of areas, and provide the basis for estimating local household waste arisings in specific waste categories, as described in Sections 2.3 and 3.3. In the discussion that follows, the names of OAC super-groups are written in italics. Locations of selected case study areas are shown in Table 2. 
Figure 2a shows demand for each OAC case study area averaged over years 2000/01-2003/04 for three commodity groups: 'Carpets', ‘Clothes Washer/Driers', and 'Women's and Girls' Outer Garments'. The demand for all three commodity groups is highest in the area representing OAC super-group Prospering Suburbs. Prospering Suburbs are areas with above average proportions of detached houses and 2+ car households, and, as the name implies, are relatively prosperous. It is therefore not surprising that this case study area has the highest demand. The lowest demand is shown in different case study areas for different commodities. For 'Carpets' the lowest demand is in the area representing City Living, whereas for 'Clothes Washer/Driers' and 'Women's and Girls' Outer Garments' lowest demand is in Constrained by Circumstances. City Living represents areas with above average proportions of single person households who are not pensioners, and above average proportions of heads of households holding a Higher Education (HE) qualification; the areas have above average proportions of flats, and below average proportions of detached houses. Constrained by Circumstances are areas with below average proportions of heads of households holding a HE qualification, and above average proportions of flats and properties that are social rented. As the name implies, this group is relatively deprived.

The relative demand for 'Clothes Washer/Driers' may be related to the institutional infrastructure, and the way in which the inhabitants of neighbourhoods use facilities provided. For example, it is probable that nearly all households in Prospering Suburbs own their own clothes washing and drying machines, whereas it is probable that some inhabitants of Constrained by Circumstances areas use launderettes. Reasoning such as this may explain the greater demand for 'Clothes Washer/Driers' in the area representing Prospering Suburbs compared to the area representing Constrained by Circumstances.

It is interesting that the case study area representing City Living shows a lower demand for 'Carpets' than the area representing Constrained by Circumstances; this may perhaps indicate a preference for hard floor coverings by the socio-economic group that make up City Living areas. This demonstrates the ability of LARA to identify the diversity of demand in local areas according to different socio-economic and demographic composition.

LARA reveals the relative contribution of each commodity category to total direct household annual material throughput in each neighbourhood. Figure 2 shows that the weight of 'Clothes Washer/Driers' is lower than that of 'Carpets' in all cases. Similarly, in every area the weight of 'Women's and Girls' Outer Garments' is less than 
the weight of 'Clothes Washer/Driers'. The relative contribution of commodities to total material throughput varies. For example, in the City Living case study area the material demand of 'Clothes Washer/Driers' is far higher in relation to the demand for 'Carpets' than in the Countryside case study area. This type of information is of especial interest to household waste management planners; in future work, the results from LARA will be mapped using a Graphical Information System (GIS) to give a visual representation of neighbourhood material flows, which could then be used to track waste arisings.

\subsection{Commodity demand in areas of contrasting relative deprivation}

Locations of the case study areas chosen to represent extreme deprivation and extreme affluence are shown in Table 2. Results from LARA (Figure 2b) show that, as expected, in comparison to the mean for England and Wales, material demand for 'Household Appliances' and 'Carpets' is higher in extremely affluent areas and lower in severely deprived areas. Figure $2 \mathrm{~b}$ also shows that there is a greater disparity between the consumption of deprived communities and highly affluent communities for 'Carpets' than for 'Household Appliances'. In the case of 'Carpets' the demand in the deprived case study area is 33\% below the mean for England and Wales, whereas for 'Household Appliances' the demand is $18 \%$ below the mean. In the extremely affluent case study area the demand for 'Carpets' is 65\% above the mean for England and Wales, and just $48 \%$ above the mean for 'Household Appliances'. This disparity might be due to cultural differences, lifestyle choices or affordability, or due to a combination of various factors. Such a discussion is beyond the remit of this paper. However, the results show that there are more likely to be high levels of inequality with regard to 'Carpets' than 'Household Appliances', and that when considering policies to reduce resource demand, it is relatively more important to consider income-specific strategies in the case of 'Carpets', than for 'Household Appliances'. For a further exploration of material inequalities see Druckman et al [16].

\subsection{Estimation of Household Waste Arisings}

This part of the paper describes how the results from LARA can be used to estimate household waste arisings. Two examples are described: first, packaging waste from drinks bottles, which can be assumed to enter the waste stream in the year of product purchase; second, waste from carpets, which must take account of residence time in households.

The trend for glass waste arisings 1996/7-2003/4 for the case study areas representing Prospering Suburbs and Constrained by Circumstances due to wine and champagne consumption is shown in Figure 3a. This shows a 
slight overall increase in both local areas with time, in line with national trends of waste arisings [41]. The highest volume of glass waste arisings are in Prospering Suburbs and the lowest in Constrained by Circumstances. This information, particularly when coupled with GIS, can be invaluable to councils when, for example, planning glass recycling facilities.

An example of waste arisings due to the average weight of 'Carpets' ( $44.4 \mathrm{~kg}$ ) purchased per household in the Constrained by Circumstances case study area in 1996/7 is plotted using the Weibull distribution (Figure 3b). The graph, based on an average product life of 10 years ${ }^{9}$, shows a near normal distribution in which the peak of wastes arise in the tenth year after purchase $(6.7 \mathrm{~kg})$. The graph shows the entire mass of carpets purchased in year one eventually entering the waste stream, with over $99.99 \%$ having been discarded by nineteenth year after purchase.

Carpet demand during the study years (1996/7-2003/4) for the Constrained by Circumstances case study area, shows a general decreasing trend with time (Figure 3c). This case study area is used to demonstrate waste arisings in the three scenarios: Low Sustainability, High Sustainability, and Constancy (as detailed in Table 3). The decreasing demand trend dominates all waste arisings scenarios until approximately 2009, as shown in Figure 3d. From approximately 2011 onwards, waste arisings are dominated by the scenario assumptions. As expected, long term waste arisings are estimated to rise in the Low Sustainability scenario, remain constant in Constancy, and fall in the High Sustainability scenario. This illustrates the importance of accurate estimations concerning future demand trends, product lifespan data, and the influence of household metabolisms when predicting future waste arisings. It also demonstrates how the model can be used in waste management planning.

\subsection{Validation of the model}

Validation of LARA is carried out in two steps: initially the accuracy of expenditure estimates of neighbourhood OAs is tested, to affirm the validity of the cross-sampling methodology employed and definition of HoCs. This is accomplished by using the model to estimate total household expenditure for England and Wales and compare it to that published by the Office of National Statistics [25]. Overall accuracy is found to be $\pm 1.5 \%$ with a chisquared goodness of fit significance of 0.995 with 7 degrees of freedom. Therefore the cross-sampling methodology and definition of HoCs were assumed to be adequate.

\footnotetext{
${ }^{9}$ Average product lifespan is taken from Holloway et al [42].
} 
Validation of the model in terms of physical units is also desirable. Specifically, in this study we carried out tests to check the validity of the two datasets from which expenditure to physical quantity conversion factors are obtained and also to test the methodology for estimating waste arisings.

The first validation involves checking the quantity of total clothing purchased in the UK calculated from LARA against the reported total quoted in a recent report on clothing consumption. The Well Dressed report [43] drew from data on imports and exports from UK Trade Data, and domestic production data from British Apparel and Textile Confederation (BATC). The first point to note is that Allwood et al [43] use data from the same dataset as LARA for imports and exports, supplemented with industry specific data. This gives credence to the assessment made here that UK Trade Data is the most appropriate source of data for use in a mass balance studies that spans across industry sectors.

According to Allwood et al [43], the 'apparent consumption' of clothing in the UK in 2004 was 992 million kg. The comparable quantity of clothing estimated according to LARA is 1,045 million kg for the year April 2004 to April 2005. The procedure for calculating this estimate from LARA is now explained. The first step is to estimate average annual household expenditure in England and Wales through LARA, which comes to £976 in 2004 current purchaser prices. This expenditure must then be converted to mass in $\mathrm{kg}$ using a consistent price basis $^{10}$. Average expenditure is calculated to be $£ 1,179$ in 2001 purchaser prices by applying the Consumer Price Index for garments. The price to mass conversion value of $£ 10.85 £ / \mathrm{kg}$ in 2001 basic prices is obtained from UK Trade Data, as described earlier. This value is then converted into purchaser prices, by adding in distributors' margins, and taxes less subsidies, giving $27.20 £ / \mathrm{kg}$. The average household demand is therefore estimated to be $43.4 \mathrm{~kg}$ in 2004. Using an estimate of 24.1 million households in the UK [44], the total clothing in the UK in 2004 is calculated, according to LARA, to be 1,045 million $\mathrm{kg}$. This is an over-estimate of $5 \%$ by comparison with Allwood et al [43]. Given the known inaccuracies, including, for example, the estimated number of households in the UK in a year not covered by a Census, and the difference caused by using different timeframes (LARA expenditures apply to April 2004-April 2005, Well Dressed? pertains to the calendar year), this is considered to be a satisfactory validation LARA's methodology and the use of UK Trade Data.

\footnotetext{
${ }^{10}$ The calculation is carried out using a 2001 purchaser price basis.
} 
A second validation was carried out in relation to the household glass waste arisings resulting from wine and champagne consumption in the SW England. The results obtained for this through LARA in 2001 are validated against comparable waste arisings for the region based on Chambers [45]. According to Chambers [45], total glass waste arisings in the region are 154,000 tonnes. Based on information obtained from British Glass, approximately $42 \%$ of this is due to wine and champagne consumption [46], and so we can calculate that 65,000 tonnes of glass in the SW region is due to wine and champagne consumption. However, this figure is based on Municipal Solid Waste (MSW) data which includes some commercial waste [47]. The percentage of commercial waste in total MSW was estimated to be $4 \%$ (excluding recycling) across all waste streams in the SW region in 2001/02 [48].

The quantity of commercial waste in MSW will, of course, vary for different waste streams, and neither regional or national data are, as far as the authors are aware, available specifically for glass waste. Therefore, we draw on data from a survey of Small and Medium Size Enterprises (SMEs) of food related businesses carried out in Hampshire in 2006 [49]. From this study, it is estimated that approximately $36 \%$ of the glass collected in glass recycling banks intended for domestic use emanates from businesses, such as bars and pubs. This estimate of $36 \%$ must be treated with caution as it has a number of limitations. In the first place, it is derived from a survey of just 162 businesses and a high proportion of waste was produced by one company; the survey was carried out in 2006 and we assume the results are applicable to 2001; the survey covers in a different region of England; it applies just to recycling banks. Nonetheless, applying this percentage figure to the estimate of total MSW in Chambers [50], gives an estimate of 42,000 tonnes of glass waste arisings due to wine and champagne consumption solely by households in SW England in 2001.

The process for calculating a comparison estimate from LARA is now explained. The average household expenditure on wine and champagne is estimated from LARA to be $£ 2.72$ per week in the SW region in 2001 . From Family Food we find the conversion value of $£ 4.80 £ /$ litre, and so the average household wine and champagne consumption is estimated to be 30 litres per annum. There were 2,086,243 households in the region according to UK Census 2001, and therefore the total consumption is estimated at $61,800,000$ litres per annum in the region. We assume all wine and champagne consumption is from $750 \mathrm{ml}$ bottles, and the average weight of a wine bottle is $0.47 \mathrm{~kg}$ [46] and a champagne bottle is $0.85 \mathrm{~kg}$ (empirical measurement), and that the proportion of wine to champagne consumption is $220: 10$ by volume [27]. 
In summary, LARA estimates that 40,000 tones of glass waste arose in SW region in 2001 due to domestic consumption of wine and champagne. This figure compares against a figure of 42,000 tonnes based on Chambers [50]. This validation exercise demonstrates that validation against waste arisings has many shortcomings, due to lack of data and the number of assumptions that must be made. However, it can be concluded, within the limits of the accuracy of the data available, that the estimates obtained from LARA are comparable to other material-specific estimates of waste arisings.

\section{Conclusion}

Policies aimed at moving towards a more resource-lean society are currently being developed and implemented in the UK at both national and local level, and the Local Area Resource Analysis model (LARA), described in this paper, has the ability to contribute to future policy-making at both these levels. At a national level, LARA enhances our understanding of what type of households are responsible for how much resource use, by relating resource use to socio-economic characteristics. This ability was illustrated in this paper through case studies of specific commodity flows in specific areas based on the UK Output Area Classification (OAC) segmentation system and also on levels of relative deprivation.

At a local level LARA is able to estimate neighbourhood resource use and associated waste arisings due to the demand for specific consumer commodities. To illustrate this, the paper described an application in which LARA was linked with a household metabolism model to estimate local waste arisings. This was demonstrated for three contrasting scenarios in which disparate assumptions were made about future product demand and the time for which materials reside in households. Such mapping of resource use is important, for example, to enable identification of the locations where specific materials arise which are suitable for repair, re-use, remanufacturing and recycling. It is also vital of course in predicting the quantity and nature of household waste arisings. In future work, we intend to enhance the local usefulness of LARA in predicting waste arisings and planning waste and recycling facilities by linking it to a Geographical Information System (GIS) model.

LARA is currently constrained in its ability to analyse at high levels of disaggregation due to the small sample size of the Expenditure Survey. A specific policy conclusion from this study is that the sample size of the Expenditure Survey should be increased in future years to further this kind of analysis. 


\section{Glossary of abbreviations}

$\mathrm{OA}$

$\mathrm{OAC}$

COICOP

CPI

$\mathrm{HoC}$

HRP

LARA
Census 2001Output Area.

UK National Classification of Census Output Areas.

Classification of Individual Consumption by Purpose

Consumer Price Index

Household Characteristics Classification

Household Representative Person (head of household)

Local Area Resource Analysis model

\section{Acknowledgements}

This research was made possible through funding from the EPSRC Sustainable Urban Environment Waste Consortium programme (Grant Number GR/S79626/01), and ESRC Research Group on Lifestyles Values and Environment (RESOLVE) (Grant Number RES-152-25-1004). Data from the 2001 Census are provided by the Commissioned Output Census Service of the Office for National Statistics (Crown Copyright 2005).

\section{References}

[1] Jackson, T. Material Concerns. Pollution, profit and quality of life: Routledge, London. 1996.

[2] Hertwich, E.G. Consumption and Industrial Ecology. Journal of Industrial Ecology. 2005 9(1): p. 1-6.

[3] Tukker, A., Huppes, G., Guinée, J., Heijungs, R., de Koning, A., Oers, L.v., Suh, S., Geerken, T., Van

Holderbeke, M., Jansen, B., et al. Environmental impact of products (EIPRO): Analysis of the life cycle environmental impacts related to the total final consumption of the EU25. Institute for Prospective Technological Studies and European Science and Technology Observatory. 2005.

[4] Bringezu, S. and Moriguchi, Y. Material Flow Analysis, In: A handbook of Industrial Ecology, R.U. Ayres and Ayres, W.A., Editors Edward Elgar: Cheltenham, UK. 2002.

[5] Powrie, W. and Dacombe, P. Sustainable waste management - what is it and how do we get there? Waste and Resources Management. 2007 (Issue WR0).

[6] Hampshire County Council. "Commitment to Change". Project Integra Business Plan 2005-2010. 2005.

[7] Sanne, C. Willing consumers - or locked-in? Policies for a sustainable consumption. Ecological Economics. 2002 42(1-2): p. 273-287.

[8] Jackson, T. Challenges for Sustainable Consumption Policy, In: Earthscan Reader in Sustainable Consumption, T. Jackson, Editor Earthscan: London. 2006.

[9] DTI. Energy White Paper: Our energy future - creating a low carbon economy. TSO. London: 2003.

[10] UNEP. Life Cycle Assessment. Available from http://www.uneptie.org/pc/pc/tools/lca.htm. Accessed 18.01.07.2003.

[11] SETAC-Europe: Second Working Group on LCIA. Best available practice regarding impact categories and category indicators in life cycle impact assessment. 1999.

[12] US EPA. Life Cycle Assessment Framework. Available from http://www.epa.gov/nrmrl/std/sab/lca/lca_brief.htm. Accessed 18.01.07.: 2006.

[13] Matthews, E., Amann, C., Bringezu, S., Fischer-Kowalski, M., Hüttler, W., Kleijn, R., Moriguchi, Y., Ottke, C., Rodenburg, E., Rogich, D., et al. The Weight of Nations: Material outflows from industrial economies. World Resources Institute. Washington DC: 2000.

[14] Todd, J. and Curran, M. Streamlined Life-Cycle Assessment: a final report from SETAC North America Streamlined LCA Workgroup. SETAC. 1999.

[15] Bartelmus, P. Dematerialization and Capital Maintenance: Two Sides of the Sustainability Coin. Wuppertal Institute. Wuppertal: 2002.

[16] Druckman, A., Sinclair, P., and Jackson, T. Household resource usage and its drivers: a highly socioeconomically disaggregated model. International Sociological Association for the XVI World Congress. 2006: 23-29 July: Durban, South Africa. 23-29 July 2006.

[17] Eurostat. Economy-wide material flow accounts and derived indicators. A methodological guide. Office for Official Publications of the European Union, Luxembourg.: 2001.

[18] Rosenblum, J., Horvath, A., and Hendrickson, C.T. Environmental Implications of Service Industries. Environmental Science and Technology. 2000 34(22): p. 4669 - 4676.

[19] Miller, R.E. and Blair, P.D. Input-output analysis: foundations and extensions. London; Englewood Cliffs, N.J.: Prentice-Hall. 1985.

[20] Leontief, W. Input-output economics. 2nd Edition. Oxford, New York: Oxford University Press. 1986. 
[21] Proops, J.L.R., Faber, M., and Wagenhals, G. Reducing CO2 Emissions. A Comparative Input-Output Study for Germany and the UK. Berlin: Springer-Verlag. 1993.

[22] Druckman, A., Sinclair, P., and Jackson, T. The Local Area Resource Analysis (LARA) model: Concepts, Methodology and Applications. RESOLVE Working Paper Series, University of Surrey. 2007.

[23] Office for National Statistics Geography Policy. 2006 Accessed 24.04.06. Available from: http://www.statistics.gov.uk/geography/census_geog.asp\#oa

[24] Office for National Statistics Census 2001. 2001 Accessed 24.04.06. Available from:

http://www.statistics.gov.uk/census2001/pdfs/glossary.pdf

[25] Office for National Statistics. Family Spending: A report on the Expenditure and Food Survey.

Basingstoke, Hampshire: Various years.

[26] United Nations. Classification of Individual Consumption According to Purpose, (COICOP). 2005.

[27] Office for National Statistics. Family Food in 2001/02. London: 2003.

[28] Office for National Statistics About PRODCOM. 2005 Accessed 24/03/06. Available from:

http://www.statistics.gov.uk/downloads/theme_commerce/PRODCOM_information.pdf

[29] Intrastat Combined Nomenclature 2005. 2004 Accessed 23/02/2006. Available from:

http://www.tulli.fi/en/03_Foreign_trade_statistics/02_CN/01_CN_2005/cn05en00.pdf

[30] Vickers, D., Rees, P., and Birkin, M. Creating the National Classification of Census Output Areas: Data, Method and Results. University of Leeds. 2005.

[31] Office of the Deputy Prime Minister. The English Indices of Deprivation 2004. London: 2003.

[32] Davis, J., Geyer, R., Ley, J., He, J., Clift, R., Jackson, T., Kwan, A., and Sansom, M. Time-dependent material flow analysis of iron \& steel in the UK. Part 2: Scrap generation \& recycling. Resources, Conservation and Recycling. 2006.

[33] Spatari, S., Bertram, M., Gordon, R.B., Henderson, K., and Graedel, T.E. Twentieth century copper stocks and flows in North America: A dynamic analysis. Ecological Economics. 2005 54(1): p. 37.

[34] Moll, H.C., Noorman, K.J., Kok, R., Engström, R., Throne-Holst, H., and Clark, C. Pursuing More Sustainable Consumption by Analyzing Household Metabolism in European Countries and Cities. Journal of Industrial Ecology. 2005 9(1): p. 259-276.

[35] SDC. Redefining prosperity: resource productivity, economic growth and sustainable development (SDC report). Sustainable Development Commission. London: 2003.

[36] Jackson, T. Motivating Sustainable Consumption: a review of evidence on consumer behaviour and behavioural change. SDRN. 2005.

[37] Jackson, T. Earthscan Reader in Sustainable Consumption. London: Earthscan. 2006.

[38] Cabinet Office. UK online Annual Report 2002. Office of the e-Envoy. Available from http://www.eenvoy.gov.uk/reports-annrep-2002/\$file/index.htm. Accessed 18.01.06. 2003.

[39] Clarke, I., Hallsworth, A., Jackson, P., de Kervenoael, R., Perez-del-Aguila, R., and Kirkup, M. Retail competition and consumer choice: contextualising the "food deserts" debate. International Journal of Retail \& Distribution Management. 2004 24(2): p. 89-99.

[40] Guy, C., Clarke, G., and Eyre, H. Food retail change and the growth of food deserts: a case study of Cardiff. International Journal of Retail \& Distribution Management. 2004 34(2): p. 72-88.

[41] Strategy Unit. Waste not, Want not: A strategy for tackling the waste problem in England. Cabinet Office. London: 2002.

[42] Holloway, S., Short, S., and Tamplin, S. Household Satellite Account (Experimental) Methodology: Chapter 10 Household Capital. Office for National Statistics. 2002.

[43] Allwood, J.M., Laursen, S.E., Rodriguez, C.M., and Brocken, N.M.P. Well dressed? The present and future sustainability of clothing and textiles in the United Kingdom. University of Cambridge Institute for Manufacturing. Cambridge: 2006.

[44] Office for National Statistics. Social Trends. London: 2005.

[45] Chambers, N., Child, R., Jenkins, N., Lewis, K., Vergoulas, G., and Whitely, M. Stepping Forward: A resource flow and ecological footprint analysis of the South West of England. Best Foot Forward. Oxford: 2005. [46] British Glass Manufacturer's Confederation. Personal email communication with Rebecca Cocking, Recycling Manager. 10.04.2006. 2006.

[47] Williams, P.T. Waste Treatment and Disposal. Chichester, UK: John Wiley \& Sons. 1998.

[48] Defra and Office for National Statistics. Municipal Waste Management Survey. London: 2005.

[49] Thomas, C.I., Banks, C.J., Dacombe, P.J., and Maycox, A. Measuring the resource potential in commercial $\&$ industrial wastes from food related businesses. Proceedings of the Waste 2006 Sustainable Waste and Resource Management Conference, Stratford upon Avon, 19-21 September 2006. 2006.

[50] Chambers, N., Child, R., Jenkins, N., Lewis, K., Vergoulas, G., and Whitely, M. Stepping Forward: A resource flow and ecological footprint analysis of the South West of England - Scenarios report. Best Foot Forward. 2005. 


\begin{abstract}
About the Authors
Angela Druckman and Philip Sinclair are research fellows at the Centre for Environmental Strategy, University of Surrey. Angela is also a member of the ESRC Research Group on Lifestyles, Values and Environment (RESOLVE). Tim Jackson is Professor of Sustainable Development at the Centre for Environmental Strategy, University of Surrey and Director of RESOLVE. He is also the Economics Commissioner on the UK Sustainable Development Commission and sits on the Environment Agency Science Advisory Panel.
\end{abstract}




\section{List of Figure Captions}

Figure $1 \quad$ System diagram.

Figure 2a Demand for selected commodities in typical OAC study areas 2000/1-2003/4.

Figure $2 b \quad$ Household durable demand in areas of contrasting relative deprivation 2000/1-2003/4.

Figure 3a Trends for household glass waste arisings for Prospering Suburbs and Constrained by Circumstances due to wine and champagne consumption.

Figure 3b Graph to show Weibull distribution of waste arisings for products purchased in 1996 with mean product residence time 10 years.

Figure 3c Average demand for carpets in the Constrained by Circumstances case study area 1996/7 to 2003/4.

Figure 3d Estimated waste arisings due to carpets for three scenarios.

\section{List of Tables}

Table $1 \quad$ Names and locations of OAC case study areas, and areas representing extremes of relative deprivation.

Table 2 Definition of household characteristics classification (HoC)

Table 3. Table to show assumptions concerning product lifespans and demand for carpets for three scenarios. 
Table 1. Names and locations of OAC case study areas, and areas representing extremes of relative deprivation.

\begin{tabular}{|c|c|c|c|c|}
\hline \multicolumn{5}{|c|}{ CASE STUDY AREAS BASED ON OAC SUPER-GROUPS } \\
\hline $\begin{array}{c}\text { OAC } \\
\text { Super- } \\
\text { Group } \\
\text { Number }\end{array}$ & $\begin{array}{c}\text { OAC Super-Group } \\
\text { Name [30] }\end{array}$ & OA Code & Postcode & $\begin{array}{c}\text { Location } \\
\text { (town/Government } \\
\text { Office Region) }\end{array}$ \\
\hline 1 & $\begin{array}{l}\text { Blue Collar } \\
\text { Communities }\end{array}$ & 00CRFL0006 & B63 2DS & $\begin{array}{l}\text { Dudley, West } \\
\text { Midlands. }\end{array}$ \\
\hline 2 & City Living & 00FNNU0018 & LE2 2AB & $\begin{array}{l}\text { Leicester, East } \\
\text { Midlands }\end{array}$ \\
\hline 3 & Countryside & 46UFGX0003 & BA14 6BR & $\begin{array}{l}\text { West Wiltshire, } \\
\text { South West }\end{array}$ \\
\hline 4 & Prospering Suburbs & 35UGFU0001 & NE22 6HH & $\begin{array}{l}\text { Wansbeck, North } \\
\text { East }\end{array}$ \\
\hline 5 & $\begin{array}{l}\text { Constrained by } \\
\text { Circumstances }\end{array}$ & 00CHFF0002 & NE9 6LY & $\begin{array}{l}\text { Gateshead, North } \\
\text { East }\end{array}$ \\
\hline 6 & Typical Traits & 31UCHG0004 & LE7 2JD & $\begin{array}{l}\text { Charnwood, East } \\
\text { Midlands }\end{array}$ \\
\hline 7 & Multicultural & 00FNNN0002 & LE5 4AD & $\begin{array}{l}\text { Leicester, East } \\
\text { Midlands }\end{array}$ \\
\hline \multicolumn{5}{|c|}{ CASE STUDY AREAS BASED ON INDEX OF MULTIPLE DEPRIVATION } \\
\hline & ative Deprivation & OA Code & Postcode & $\begin{array}{c}\text { Location } \\
\text { (town/Government } \\
\text { Office Region) }\end{array}$ \\
\hline Extreme $\mathrm{c}$ & privation & 00BYFE0010 & L8 ORP & $\begin{array}{l}\text { Liverpool, North } \\
\text { West }\end{array}$ \\
\hline Extreme a & fluence & 21UHHX0002 & TN225NE & Uckfield, South East \\
\hline
\end{tabular}


Table 2. Definition of household characteristics classification (HoC)

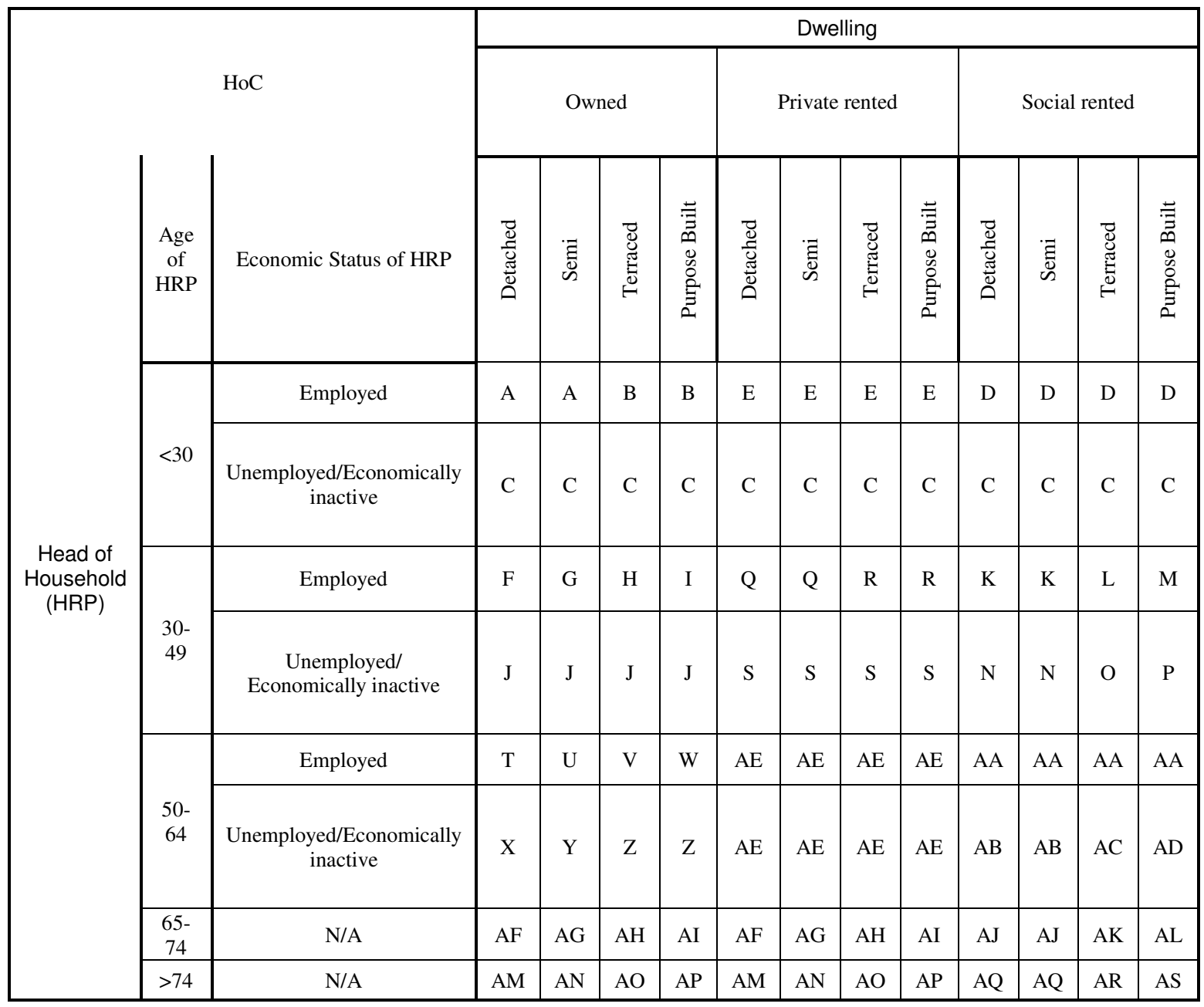

\section{Explanatory Notes}

Detached: Detached house or bungalow.

Semi: Semi-detached house or bungalow

Terraced: Terraced house or bungalow; flat, maisonette or apartment which is part of a converted or shared house; or in a commercial building.

Purpose Built: Purpose built flat, maisonette or apartment, caravan or other mobile structure.

Private Rented: Rented, private or rent free

Social Rented: Rented, from council or Registered Social Landlord or Housing Association.

Employed: Full-time/part-time employee and self employed 
Table 3. Table to show assumptions concerning product lifespans and demand for carpets for three scenarios.

\begin{tabular}{|c|c|c|c|}
\hline Scenario & Years & Product Demand & Product Lifespan $^{\mathrm{a}}$ \\
\hline \multirow[t]{3}{*}{ High sustainability } & Pre 1996/7 & $\begin{array}{l}\text { As found from LARA for } \\
1996 / 7\end{array}$ & 10 years \\
\hline & $1996 / 7-2003 / 4$ & As found from LARA & \multirow[b]{2}{*}{$\begin{array}{l}\text { Increases by } 2.5 \% \\
\text { p.a. }\end{array}$} \\
\hline & Post 2003/4 & Decreases by $2 \%$ p.a. & \\
\hline \multirow[t]{3}{*}{ Low sustainability } & Pre $1996 / 7$ & $\begin{array}{l}\text { As found from LARA for } \\
1996 / 7\end{array}$ & 10 years \\
\hline & $1996 / 7-2003 / 4$ & As found from LARA & \multirow{2}{*}{$\begin{array}{l}\text { Decreases by } 1.0 \% \\
\text { p.a. }\end{array}$} \\
\hline & Post 2003/4 & Increases by $2 \%$ p.a. & \\
\hline \multirow[t]{3}{*}{ Constancy } & Pre $1996 / 7$ & $\begin{array}{l}\text { As found from LARA for } \\
1996 / 7\end{array}$ & 10 years \\
\hline & $1996 / 7-2003 / 4$ & As found from LARA & \multirow[b]{2}{*}{ Constant (10 years) } \\
\hline & Post 2003/4 & $\begin{array}{l}\text { Constant, as found from LARA } \\
\text { for } 2003 / 04\end{array}$ & \\
\hline
\end{tabular}

${ }^{a}$ Average product lifespan is taken from Holloway et al [42]. 


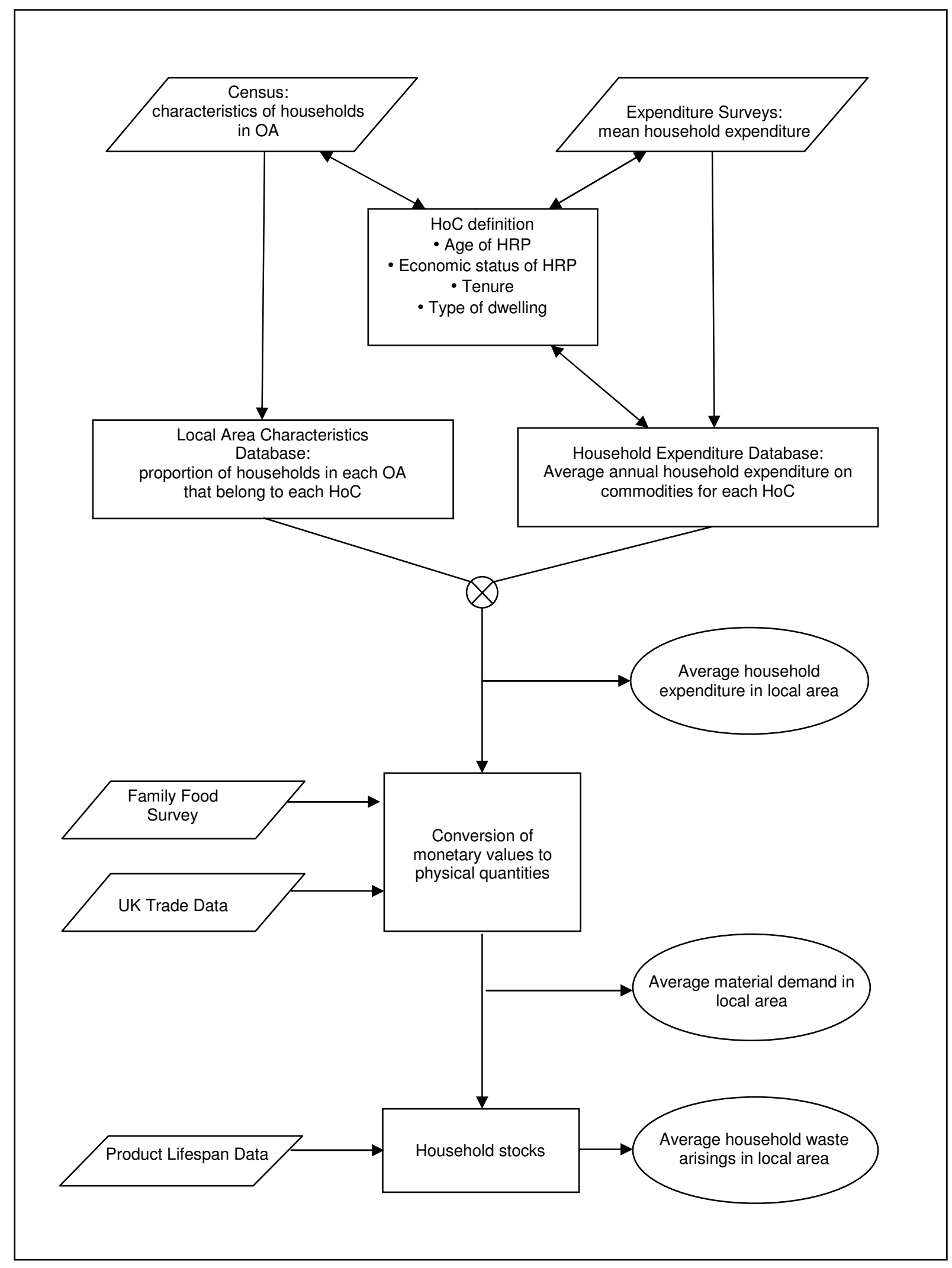

Figure 1. System diagram 


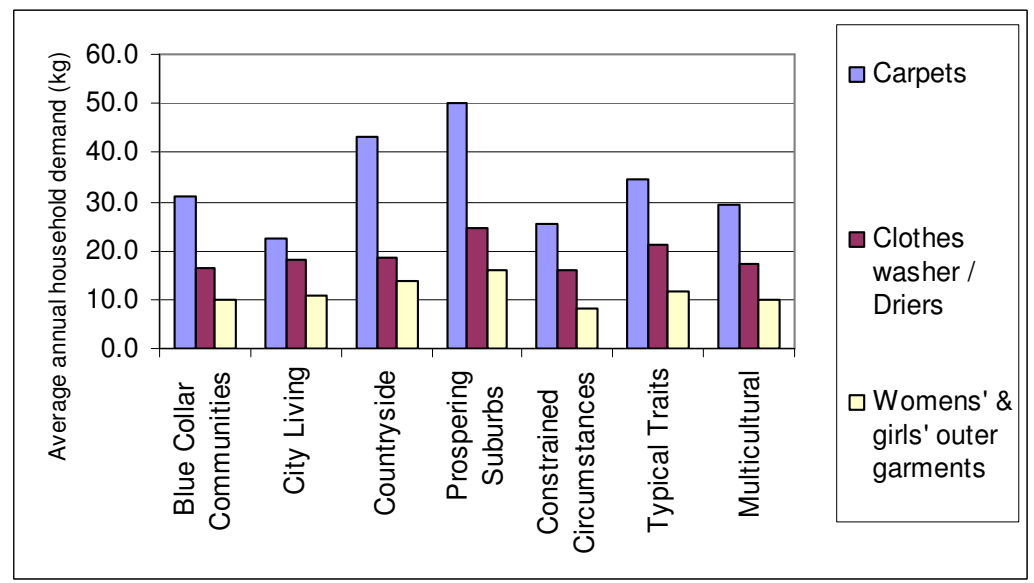

Figure 2(a). Demand for selected commodities in typical OAC study areas 2000/1-2003/4

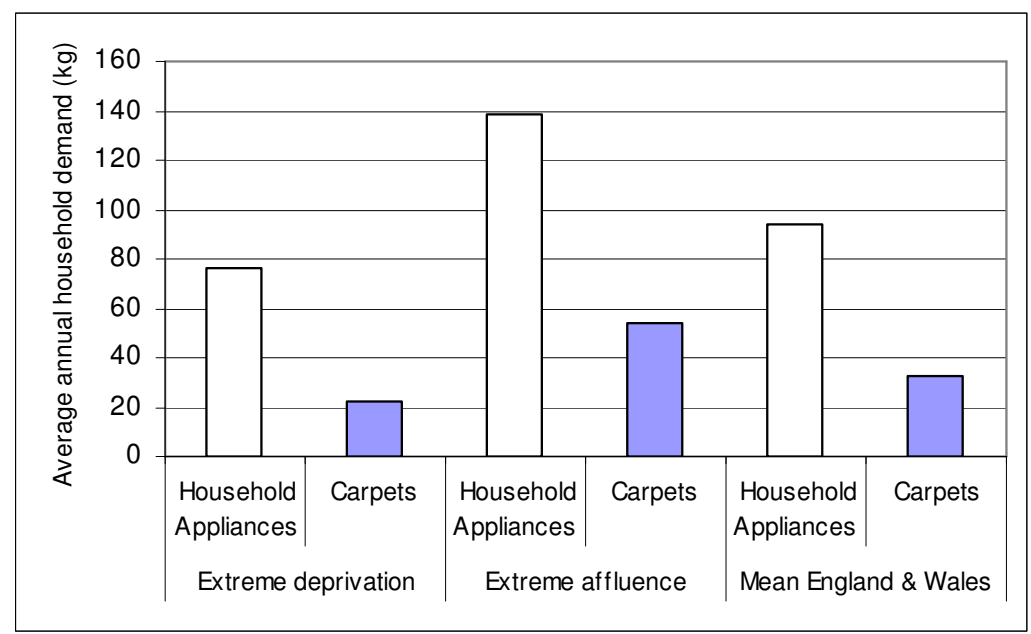

Figure 2(b). Household durable demand in areas of contrasting relative deprivation 2000/1-2003/4 


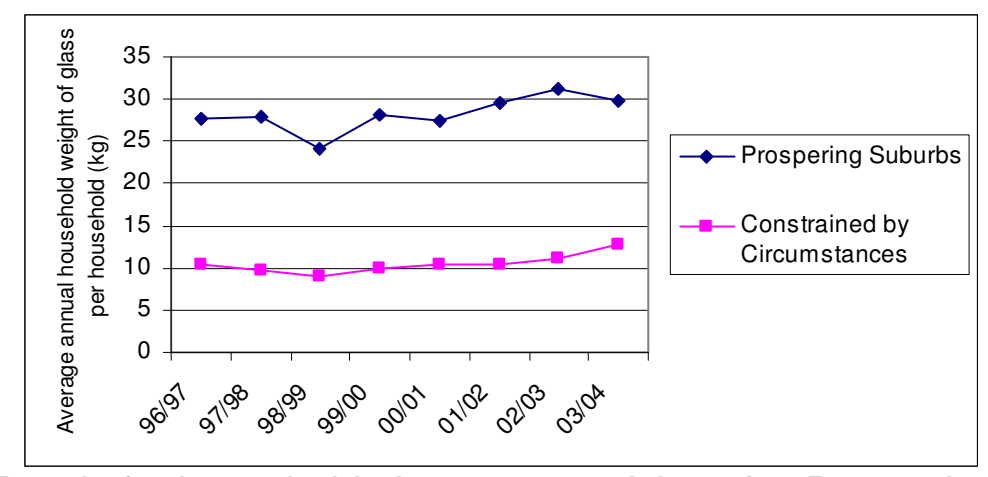

Figure 3(a). Trends for household glass waste arisings for Prospering Suburbs and Constrained by Circumstances due to wine and champagne consumption

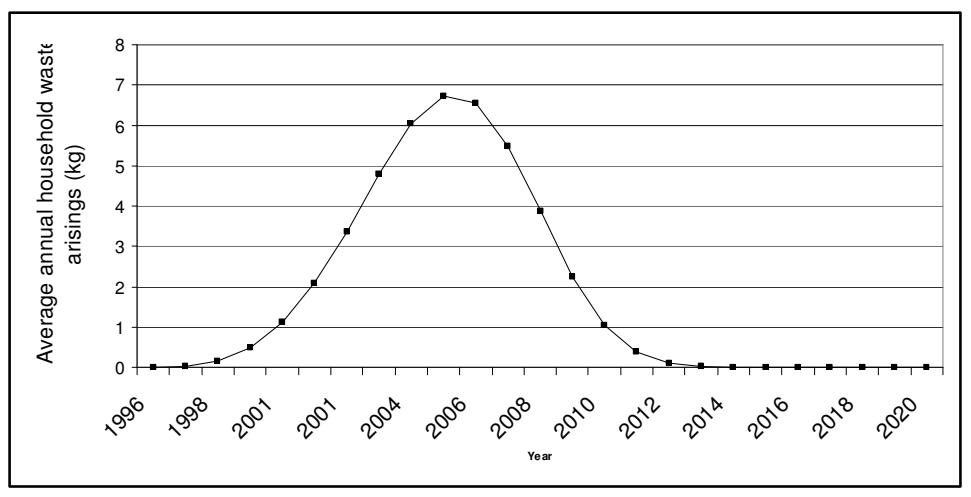

Figure 3(b) Graph to show Weibull distribution of waste arisings for products purchased in 1996 with mean product residence time 10 years

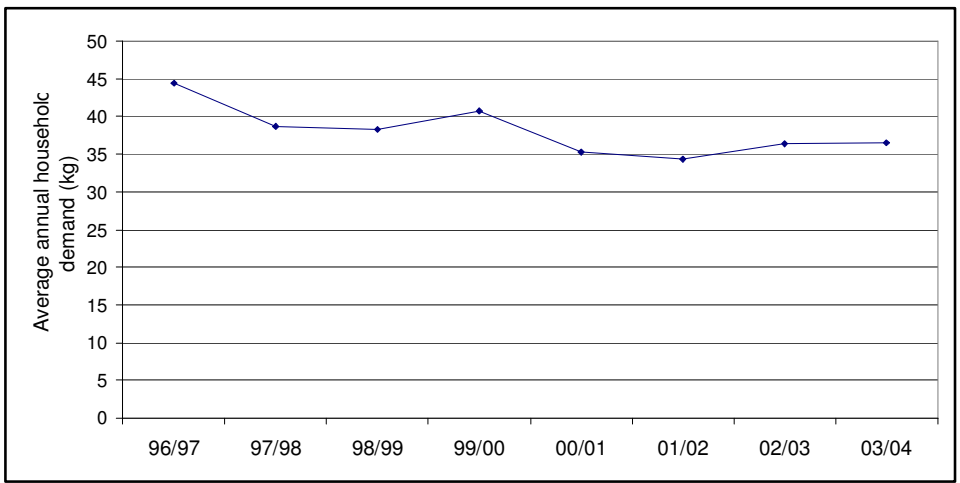

Figure 3(c). Average demand for carpets in the Constrained by Circumstances case study area $1996 / 7$ to $2003 / 4$

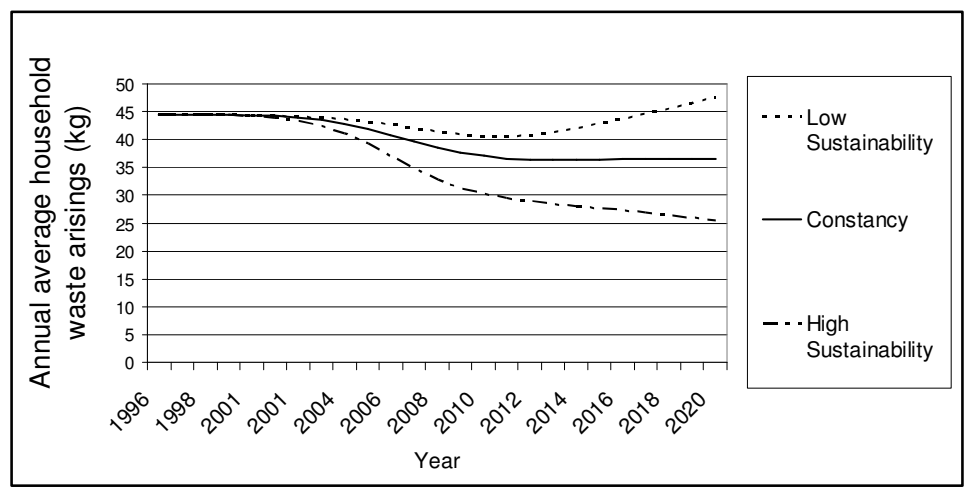

Figure 3(d). Estimated waste arisings due to carpets for three scenarios 